\title{
Stress-The hidden pandemic for school children and adolescents in India during COVID-19 era
}

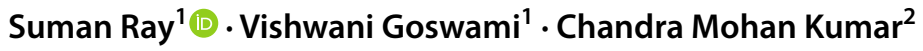

Accepted: 27 January 2022

(c) The Author(s), under exclusive licence to Springer Science+Business Media, LLC, part of Springer Nature 2022

\begin{abstract}
The effects of coronavirus are not just physical but also psychological in all age groups and more so common among children. Some children may have had experience of quarantine restrictions during this COVID-19 pandemic. Due to increased digital connections 'emotional contagion' where the distress and fear experienced by one spread to another person may also be common in children. The present study aims to determine whether COVID-19 pandemic and the lockdown has caused stress and affected mental health of children and youth. The current study assessed stress in children and youth between 9 and 18 years age based on Short Self-Rating Questionnaire (SSRQ) during the COVID-19 pandemic. The study design was an observational study, a descriptive cross-sectional study using online survey. Total 369 schools children participated in the survey. Score Scale and analysis was done to categorize the stress levels as Low, Moderate and Severe. Data analysis based on the total score levels (Delhi+Mathura zone, $n=369$ ) showed 30.08\% ( $n=111)$ students with Low stress level, 62.87\% $(n=232)$ within Moderate stress level and 7.08\% (n=26) with severe stress level. Students T Test revealed that there was a significant difference $(p \leq 0.04)$ of the stress level male vs. female in total (Delhi + Mathura zone combined). However, the stress level was not significantly different between Delhi and Mathura zone alone. It is utmost to give primary importance to address the stress issues in children and adoloscents in the current scenario. Inclusion of Intervention strategies that are empirically supported and culturally appropriate as per the need of the communities for children and families may be helpful.
\end{abstract}

Keywords Stress $\cdot$ children $\cdot$ youth $\cdot$ psychological $\cdot$ mental $\cdot$ health policy

\section{Introduction}

COVID-19, the greatest pandemic of last 100 years, although generally believed to have milder course in children in terms of disease severity, has multifaceted impacts on children that is psychological, mental, physical, social and cultural. Due to COVID-19 pandemic, many children have had no physical

Suman Ray

sumanitrc@gmail.com; suman@nistads.res.in

Vishwani Goswami

vishwanigoswami@gmail.com

Chandra Mohan Kumar

cmkumar@aiimspatna.org; cmkumar1@rediffmail.com

1 CSIR-National Institute of Science Communication and Policy Research (CSIR-NIScPR), formerly known as National Institute of Science Technology and Development Studies (CSIR-NISTADS), Pusa Gate, K.S. Krishnan Marg, New Delhi 110 012, India

2 All India Institute of Medical Sciences, Patna 801507, India access to friends, peers, schoolmates and relatives for past one and half year and most of the school curricular activities were being done online on digital platform. Limited or no opportunity for outdoor games and socialization may have a great effect on mental health of children, making them easily bored, angry and sometimes frustrated and hence, vulnerable to mental stress. Due to increased digital connections 'emotional contagion' where the distress and fear experienced by one spread to another person may also be common in children. Besides, some children may have had experience of quarantine restrictions during this COVID-19 pandemic, also be another factor leading to mental stress. All these together has multifaceted impacts on children which may be psychological, mental, physical, social and cultural. The effects of coronavirus are not just physical but they are also psychological in all age groups but more so among children. A recent study points towards the critical need to respond to the global mental health effects on children and adolescents at the global level due to COVID-19 pandemic (Racine et al., 2021). This is in fact a global call to action, hence, there is a 
need for equitable mental health care for all children across the world (Benton et al., 2021).

Although there is paucity of data regarding prevalence of stress among Indian children prior to COVID-19 pandemic, it is presumed to be in line of global figures. Earlier studies have estimated that the prevalence of depression and anxiety, of the most common mental health conditions of childhood, were $8.5 \%$ for depression and $11.6 \%$ for anxiety before the COVID-19 pandemic (Tiirikainen et al., 2019). A meta-analysis for psychiatric disorders estimated the global prevalence rates from 27 countries found that $2.6 \%$ of youth had depressive disorder and $6.5 \%$ had any anxiety disorder among children and adolescents (Polanczyk et al., 2015). According to UNICEF, $41 \%$ of India's population is less than 18 years of age. In a huge country with limited facilities for pediatric psychiatrists and psychologists, the treatment gap for mental disorders still remains very high. These facts raise issues pertaining to mental health status of our children post COVID-19.

For many children, school is a place where interactions with other children and their teacher's a great mental support and in some schools they can also access support services such as counselling.

Higher levels of anxiety, stress, and depression after the stay-at-home order post COVID-19 could lead to further psychological trauma besides mental health impact of raging pandemic itself. Younger age, female gender, and caregiver status have greater degree of stressfulness due to the pandemic. Their mental health issues cannot be neglected during the pandemic and post-pandemic, their health and wellbeing is the concern today. A recent report support that frontline workers and children both were among those most at risk of mental health issues during the pandemic. In the United States, particularly among adolescents, the prevalence of mental disorders during pandemic included depression, anxiety, and substance abuse and supported by other studies across the globe that showed similar increases in depression and anxiety (Editorial., 2021).

The present study has primary objective of determining whether COVID-19 pandemic and the lockdown has caused stress and affected mental health of children aged between 9 and 18 years.

\section{Methodology}

\section{Study Design}

The present study assessed stress in children and youth between 9 and 19 years age based on Short Self-Rating Questionnaire (SSRQ) during the COVID-19 pandemic. The study design was observational study a descriptive cross-sectional study using online survey. Assessment of stress in children and youth between 9 and 19 years age was done based on Short Self-Rating Questionnaire (Osika et al., 2007) and the methods used were online survey, data extraction, collection and analysis. Prior one-to-one interaction was done with Schools Principals/Teachers for their consent and participation for the survey study. Random sampling method was followed for the survey. The survey was done during July, 2021. Figure 1 demosntrates the flow chart of the survey method in the study.

\section{Sample Size}

Based on 51.3\% prevalence of stress disorder in meta-analysis by Sarkar et al. (2017), a sample size of 384 was determined for estimating the expected proportion of 0.51 with $5 \%$ absolute precision and 95\% confidence using statulator. Government (two) and Private Schools (three) affiliated to Central Board of Secondary Education (CBSE) total 5 schools from two zones, were randomly selected and invitation to participate/permission to conduct study on their pupils, were sent to school authorities/Principals. Out of 10 schools , 7 responded and granted permission (5 in Mathura Zone and 2 in Delhi Zone). Presuming 10 percent non

Based on $51.3 \%$ prevalence of stress disorder in metaanalysis by Sarkar et al. (2017), a sample size of 384 was determined for estimating the expected proportion of 0.51 with $5 \%$ absolute precision and $95 \%$ confidence using statulator
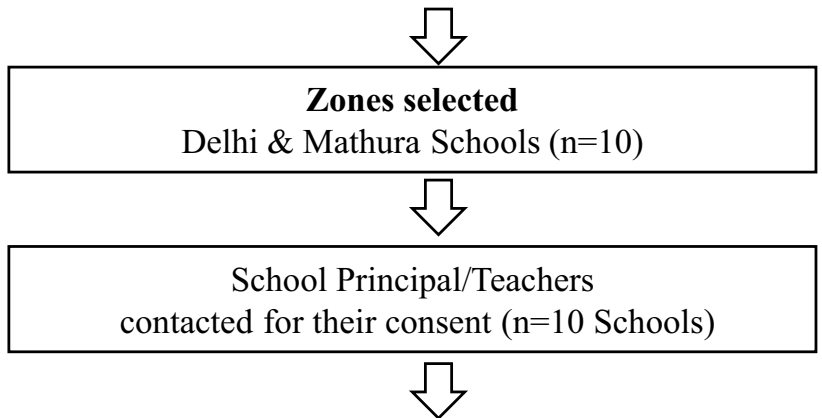

Google Doc Link (survey Questionnaire) shared with students of class 6-12 ${ }^{\text {th }}$ standard ( $\mathrm{n}=10$ Schools)

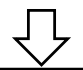

Complete responses received, $6-12^{\text {th }}$ standard students ( $\mathrm{n}=7$ Schools, $\mathrm{n}=369$ students)

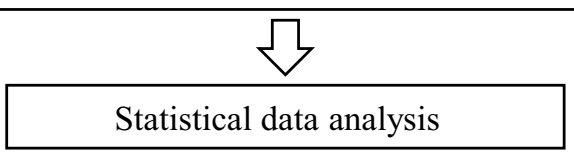

Fig. 1 Complete flow chart of the survey method for the responses received from the schools and students who participated in the study 
response the questionnaire was to be shared with 422 students. In 7 schools with help of stratified random sampling in each class from 6th to class 12 th, every 5 th student, ( 8-9 students from each class depending on their class strength) to which SSR Questionnaire was sent online.

Out of 422, 369 (313 in Mathura Zone and 56 in Delhi Zone) responded and all complete responses $(n=369)$ were included in data analysis.

\section{Ethical Considerations}

The online questionnaire was administered to students with permission of respective school authorities. The informed consent of parents as well as informed assent of children were obtained online with sharing participant information sheet and informed consent form online along with the questionnaire.

\section{Score Scale and Analysis}

Total 21 questions were used for the survey and the score range from 0-3 were given for each response against each Question. Details of the scoring against each of the 21 Questions is given in Supplementary Table 1. The stress levels were categorized according the Score scale: Low (0-21), Moderate (22-35), Severe (36 \& above). Students TTest was used for statistical analysis, with $p \leq 0.05$ as a significant difference value. Table 3 A \& B demonstrates the stress levels due to COVID-19 (low, moderate and severe) and the total responses with questions in stratified age groups.

\section{Results}

The responses were collected from the school children of two zones-Delhi zone, a metropolitan city and Agra zone of UP, India. Figure 2(A) represents the overall reponse and score levels categrized as low, mederate and sever stress levels.

\section{Age and Gender}

Age range of the students who responded were from 9-18 years, 218 were male students and 151 were female students. The details of the response from schools and students who participated in the survey is shown in Table 1 and Fig. 2(B). The trend of age vs. score values is depicted in Fig. 2(C).

\section{Urban vs. Remote \& Rural}

We found that most of the response were from Mathura zone $(n=313)$ as compared with Delhi zone $(n=56)$. Mathura zone belong to remote area whereas Delhi zone is a metropolitan city. Statistical analysis of the survey responses based on the scores of the respondents revealed that there was no zone wise difference in the stress levels. Table 1 shows the details of the Delhi and Mathura zone responses, from schools and students in stratified age groups who participated in the survey.

\section{Male vs. Female Stress Levels}

Table 2 depicts the statistical analysis of the survey responses based on the scores of the respondents. Score Scale and analysis with Students TTest revealed that there was a significant difference $(p \leq 0.04)$ of the stress level in male compared with female students in total (Delhi + Mathura zone combined). However, the stress level was not significantly different between Delhi and Mathura zone. The stress level was found to be predominant $(p \leq 0.001)$ in 17-18 years age group of male students only. Figure 2 shows stress response in $\%$ in stratified age groups and children tested COVID-19 positive or in quarantine due to COVID-19 in past.

\section{Low, Moderate and Severe Stress Levels}

Data analysis based on the total score levels (Delhi+Mathura zone, $n=369)$ showed $30 \%(n=111)$ students with low stress level, 63\% $(n=232)$ within moderate stress level and 7\% (n=26) with severe stress level (Fig. 2). Most of the students were found to be in the moderate stress level, a matter of great concern for the parents, teachers and healthcare authorities. Although, only $7 \%$ students are in the category of severe stress, it is alarming situation to prevent future pandemic due to stress among children. Stress response in \% in stratified age groups and children tested COVID-19 positive or in quarantine due to COVID-19 in past as demonstrated in Fig. 2 indicates that 15-16 years of age group children were most affected with moderate stress levels. The stress response in \% in stratified age groups in children tested COVID-19 positive or in quarantine due to COVID-19 in past showed that the age groups 13-14 years was mostly affected with severe stress levels (Fig. 2).

\section{Trend of Stress Response}

Figure 3 shows trend of stress response in male vs. female, the most frequent response trend against each Question of the Survey Questionnaire and also the responses of children 
Fig. 2 Stress level analysis of the respondents: (A) Stress response in \% (Delhi + Mathura Zone combined)-Low (30\%), Moderate (63\%) and Severe (7\%) stress level (B) Stress response in \% in stratified age groups (C) Stress response in $\%$ in stratified age groups in children tested COVID-19 positive or in quarantine due to COVID-19 in past.
(A)

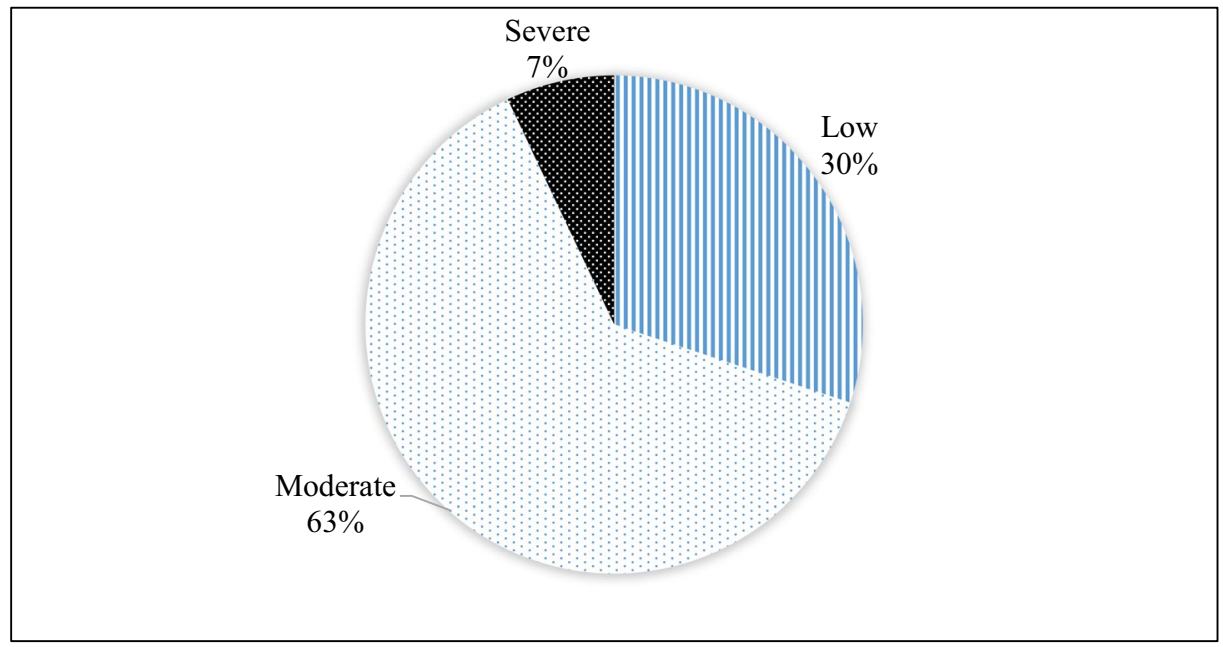

(B)

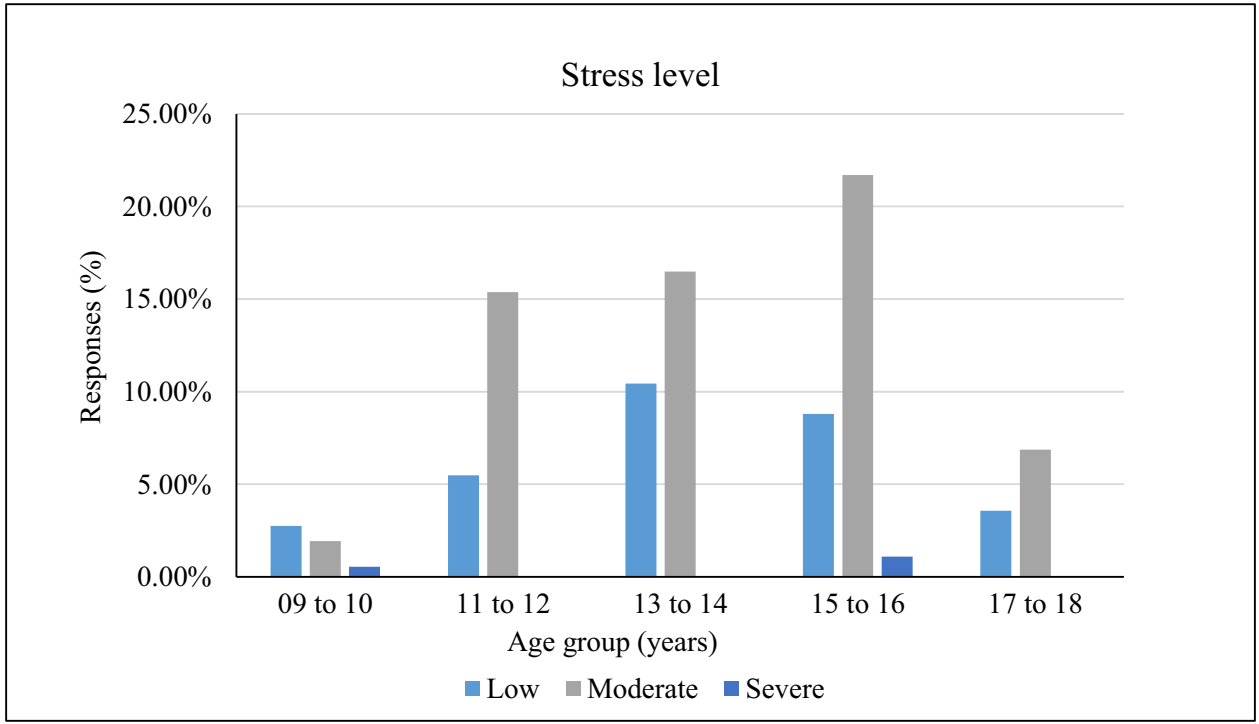

(C)

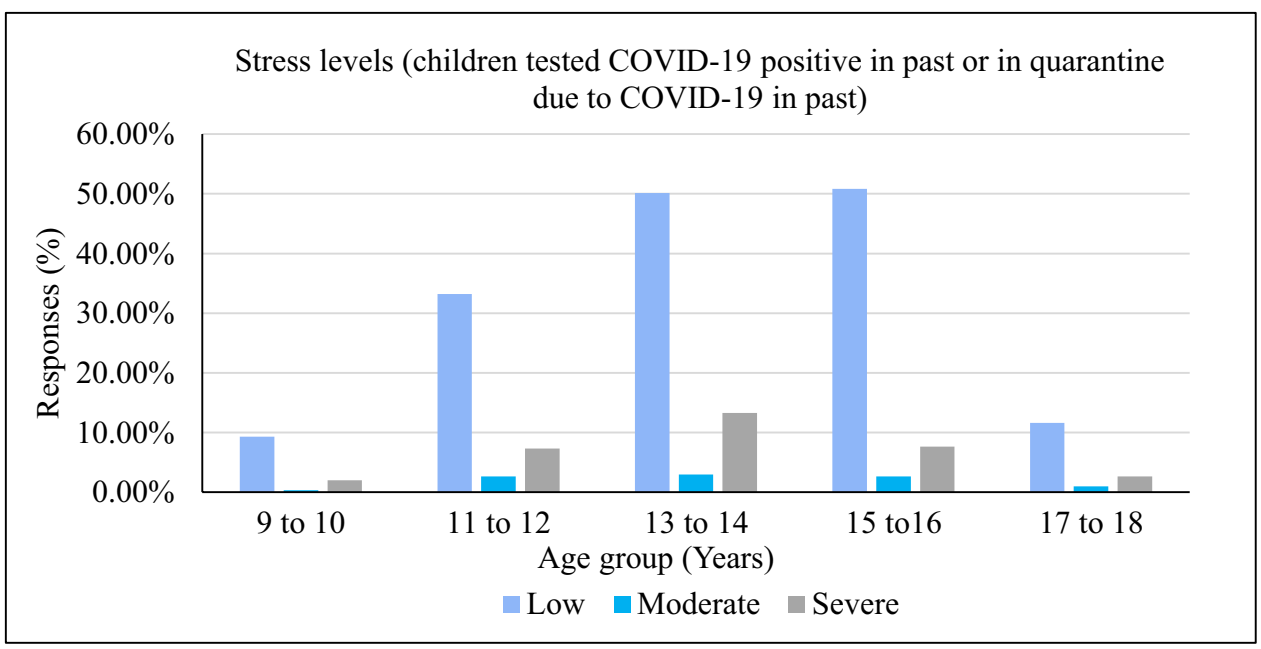


Table 1 Survey response details and score scale (A) Showing the details of the response from schools and students participated in the survey. (B) Survey response of students in stratified age groups $(\mathrm{C})$ Stress level of the responses of the students participated in the survey in age groups and (D) Stress level in stratified age groups.
(A)

Total number of schools participated in the survey $=7$ (of the 10 schools approached)

Total number of students responded $=369$ (n)

Age range of the students who responded $=9-18$ years

$\begin{array}{cll}\text { Region } & \text { Number of students responded } & \\ & \text { Male } & \text { Female } \\ \text { Mathura } & 187 & 126 \\ \text { Delhi } & 31 & 25 \\ \text { Total } & 218 & 151\end{array}$

(B)

Survey response of students in stratified age groups

(responses excluded that did not reveal their age, $n=5$ )

\begin{tabular}{llllll} 
Regions & \multicolumn{2}{l}{ Age group in years } \\
& $9-10$ years & $11-12$ years & $13-14$ years & $15-16$ years & $17-18$ years \\
Delhi (n) & 0 & 18 & 6 & 17 & 14 \\
Mathura (n) & 19 & 67 & 101 & 98 & 24 \\
Total (n) & 19 & 85 & 107 & 115 & 38
\end{tabular}

(C)

\begin{tabular}{llll}
\multicolumn{3}{l}{ Score scale: Low (0-21), Moderate } & $(22-35)$, Severe (36 \& above ) stress \\
Total, $n=369$ & Low & Moderate & Severe \\
& $30.08 \%(111)$ & $62.87 \%(232)$ & $7.04 \%(26)$ \\
Male, $n=218$ & $29.81 \%(65)$ & $61.46 \%(134)$ & $8.71 \%(19)$ \\
Female, $n=151$ & $31.78 \%(48)$ & $63.57 \%(96)$ & $4.63 \%(7)$
\end{tabular}

(D)

Score scale in stratified age groups: Low (0-21), Moderate (22-35), Severe (36 \& above ) stress (responses excluded that did not reveal their age, $n=5$ )

\begin{tabular}{llllll} 
Total=364 & $9-10$ years & $11-12$ years & $13-14$ years & $15-16$ years & $17-18$ years \\
Low & $2.74 \%(10)$ & $5.49 \%(20)$ & $10.43 \%(38)$ & $8.79 \%(32)$ & $3.57 \%(13)$ \\
Moderate & $1.92 \%(7)$ & $15.38 \%(56)$ & $16.48 \%(60)$ & $21.70 \%(79)$ & $6.86 \%(25)$ \\
Severe & $0.54 \%(2)$ & $0.024 \%(9)$ & $0.024 \%(9)$ & $1.09 \%(4)$ & $0 \%(0)$ \\
\hline
\end{tabular}

tested COVID-19 positive or in quarantine due to COVID-19 in past. Overall male students were more affected with stress as per the feedback survey responses.

\section{Discussion}

Our findings revealed that moderate level of stress was most prevalent in children and adolescents. This is more significant in males as compared with the females. Finding of the study is supported by a recent study that showed high rates of anxiety, depression, and post-traumatic symptoms among children post COVID-19 pandemic impact (Marques de Miranda et al., 2020). Another study based on the systematic review of depression, anxiety, and stress among medical students in India showed that the pooled prevalence rate of anxiety from four studies $(n=686)$ was $34.5 \%$ and the pooled prevalence rate of stress from 28 studies $(n=$ 5354) was $51.3 \%$ (Sarkar et al., 2017). Our survey study of the children and adolescents showed the prevalence rate of stress level Low (30\%), Moderate (63\%) and Severe (7\%).
The trend of stress response in male vs. female varied significantly with males more prone to severe stress compared with the females.

From various studies as quoted in the systemic review by Marques de Miranda et al. (2020), 13 to 47\% children had anxiety and $12-48 \%$ have depressive illness. Mental disorders has been indicated as one of the leading causes of non-fatal disease burden in India (Dandona, 2020). A recent cross-sectional study also highlights the impact of the COVID-19 Pandemic on Mental Health and Quality of Life among local residents in Liaoning Province, China (Zhang, 2020). Another study revealed the highest tendency toward psychological problems was in the 14 to 20 yearsold group in comparison to the 21 to 35 years-old group (Liang et al., 2020).

Mental health and psychosocial considerations during the COVID-19 outbreak was given a priority by WHO which advised to stay connected and maintain social networks and pay attention to own needs and feelings during in times of stress. The needs of vulnerable groups, including those with severe mental illness, learning difficulties, 
Table 2 Statistical analysis of the survey responses based on the scores of the respondents (A) Male vs. Female; Delhi vs. Mathura. There is a significant difference $(p \leq 0.041)$ of the stress level male vs. female in total but not Delhi vs. Mathura zone. (B) Male vs. Female score levels in stratified age groups. The stress level was found to be predominant $(p \leq 0.001)$ in $17-18$ years age group of male students only. (C) Total responses in children tested COVID-19 positive or in quarantine due to COVID-19 in past

\begin{tabular}{|c|c|c|c|c|}
\hline & \multicolumn{4}{|c|}{$P$ value } \\
\hline \multicolumn{5}{|l|}{ Total (Delhi+ Mathura) } \\
\hline Male vs. Female & \multicolumn{4}{|l|}{0.04} \\
\hline \multicolumn{5}{|l|}{ Delhi } \\
\hline Male vs. Female & \multicolumn{4}{|l|}{0.41} \\
\hline \multicolumn{5}{|l|}{ Mathura } \\
\hline Male vs. Female & \multicolumn{4}{|l|}{0.76} \\
\hline \multicolumn{5}{|l|}{ Delhi vs. Mathura } \\
\hline a. Male vs. Male & \multicolumn{4}{|l|}{0.20} \\
\hline b. Female vs. Female & \multicolumn{4}{|l|}{0.43} \\
\hline c. Male vs. Female & \multicolumn{4}{|l|}{0.13} \\
\hline \multicolumn{5}{|l|}{ (B) } \\
\hline Male vs. Female & \multicolumn{4}{|c|}{$P$ value } \\
\hline $9-10$ years & \multicolumn{4}{|l|}{0.31} \\
\hline $11-12$ years & \multicolumn{4}{|l|}{0.06} \\
\hline 13-14 years & \multicolumn{4}{|l|}{0.29} \\
\hline $15-16$ years & \multicolumn{4}{|l|}{0.42} \\
\hline $17-18$ years & \multicolumn{4}{|l|}{0.001} \\
\hline \multicolumn{5}{|l|}{ (C) } \\
\hline Questions & Yes & No & Maybe & $\begin{array}{l}\text { Total } \\
\text { Responses }\end{array}$ \\
\hline 22.I was tested positive for COVID-19 earlier/ कोवडि-19 की मेरी पहली जांच रपिर्ट्ट पॉजीटवि आई थी। & 27 & 243 & 31 & 301 \\
\hline $\begin{array}{l}\text { 23.I was suffering from mental illness or brain disorders before COVID-19 pandemic/ कोवडि-19 } \\
\text { महामारी से पहले मै मानसकि रोग अथवा मस्तष्कि रोग से पीड़ित था/ थी। }\end{array}$ & 56 & 245 & 0 & 301 \\
\hline 24.I was in quarantine earlier due to CVOID-19/ कोवडि-19 महामारी के कारण मै क्वारंटीन में था/ थी। & 72 & 229 & 0 & 301 \\
\hline
\end{tabular}

and neuro developmental disorders etc. due to COVID-19 pandemic need attention (Editorial., 2020). The exposure of children to online screens, television etc. should be reduced. According to The Indian Association for Child and Adolescent Mental Health, children need reassurance that pandemic period will be over soon. Hence, parents and caregivers to be calm and proactive so that the child feel free to express their emotions, and by monitoring both their own and their children's behavior as well (UNICEF, 2020b).

COVID-19 pandemic has led to various concerns regarding its mental health effect on patients with psychiatric disorders and also the health-care workforce. Psychological distress among those already suffering from psychiatric syndromes is on rise due to coronavirus-induced lockdown, isolation and quarantine recently reported in India (Melo and Soares, 2020). A narrative review on the challenges and burden of the Coronavirus 2019 (COVID-19) pandemic for child and adolescent mental health showed that COVID19-associated mental health risks to disproportionately hit children and adolescents who are already disadvantaged and marginalized (Fegert et al., 2020).

Due to closure of schools there has been an increase in screen time, sedentary life, not following daily routine which are also having both physical and psychological effects on children. Children are also being exposed to the media coverage about coronavirus which might create fear among children due to the unpredictability and uncertainty of the illness. In such a scenario, parents and immediate caregivers specially need to take up major responsibility to help children in distress and hence, need to create a sense of normalcy at home. This may be done several ways that include play involving some physical workouts, academic activities which is joyable and participative, interaction with family members, creative writing, socialization that can connect to friends and relatives.

Data from the longitudinal studies and intervention trials in this population also need to be consolidated to further confirm the current study which includes crosssectional survey study with students from two zone only, 
की

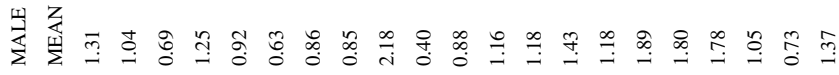
质

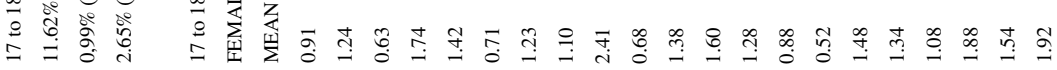

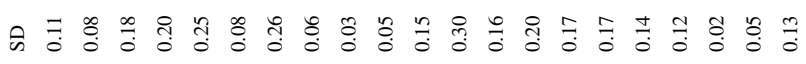

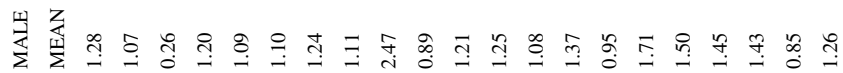
危

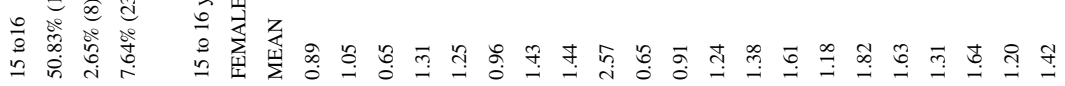

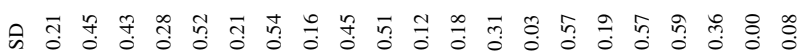

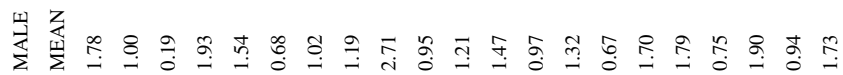
语

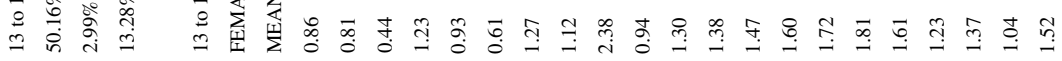

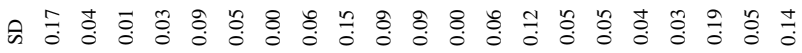

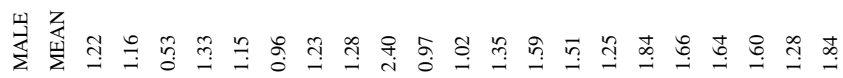

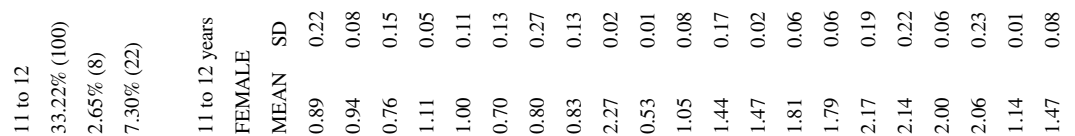

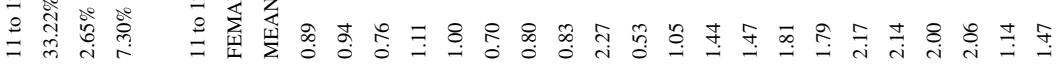

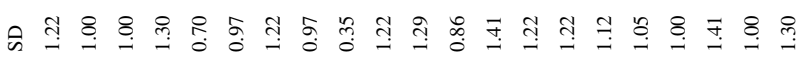

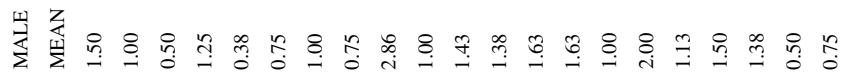

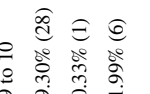

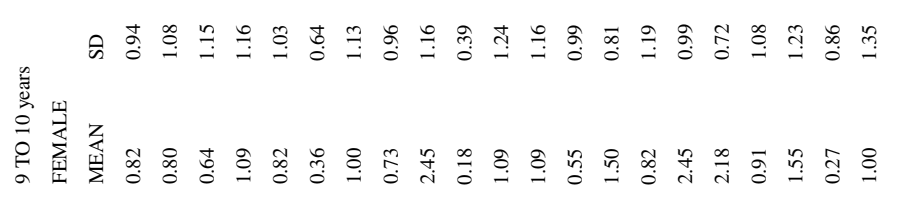

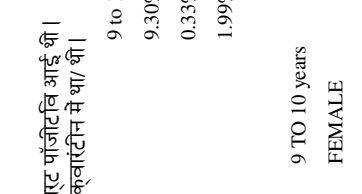


Fig. 3 A Trend of stress response in Male vs. Female, Mean Score value in the $\mathrm{Y}$ axis against each of the 21 questions in the $\mathrm{X}$ axis (B) Trend of stress response in Male vs. Female

Mean Score value in the $\mathrm{Y}$

axis against each of the 22,24

COVID-19 specific questions

in the $\mathrm{X}$ axis $(\mathbf{C})$ Age versus score values of the respondents $(n=365)$ indicating the trend of stress levels with respect to age, 4 respondents did not mention their age hence, not included in the graph. D Most frequent response trend against each Question of the Survey Questionnaire
(A)

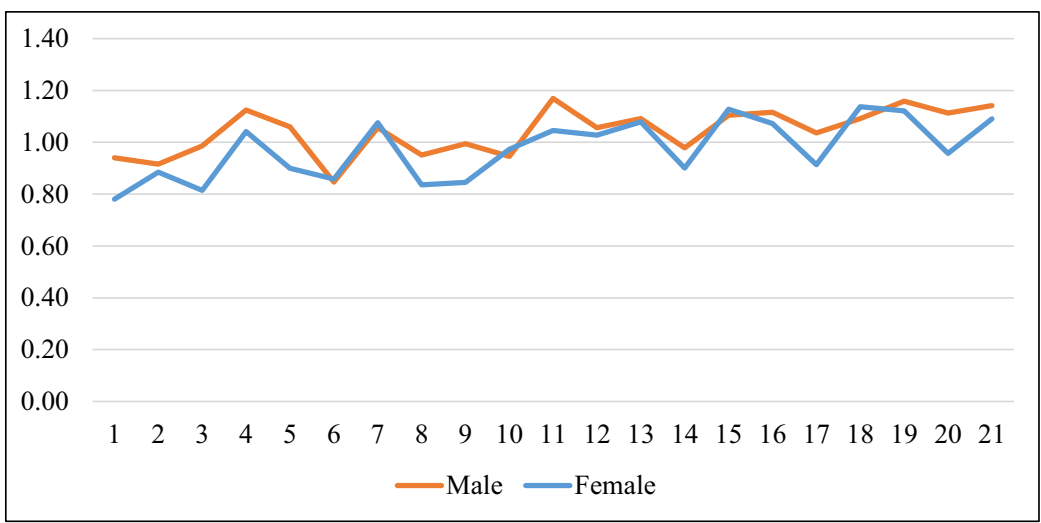

(B)

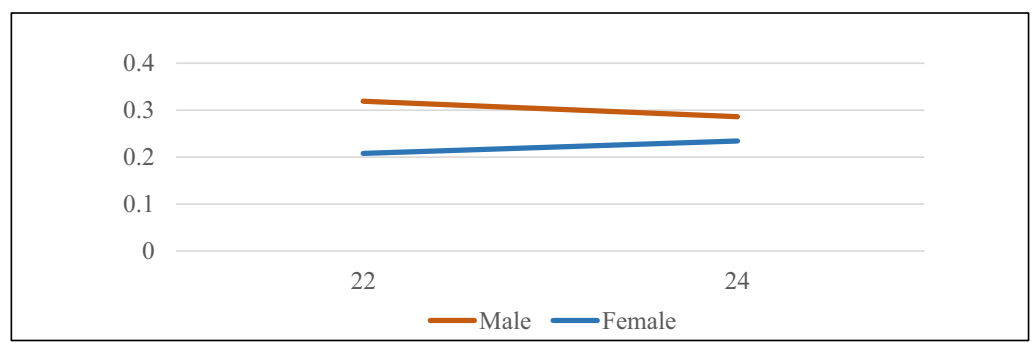

(C)

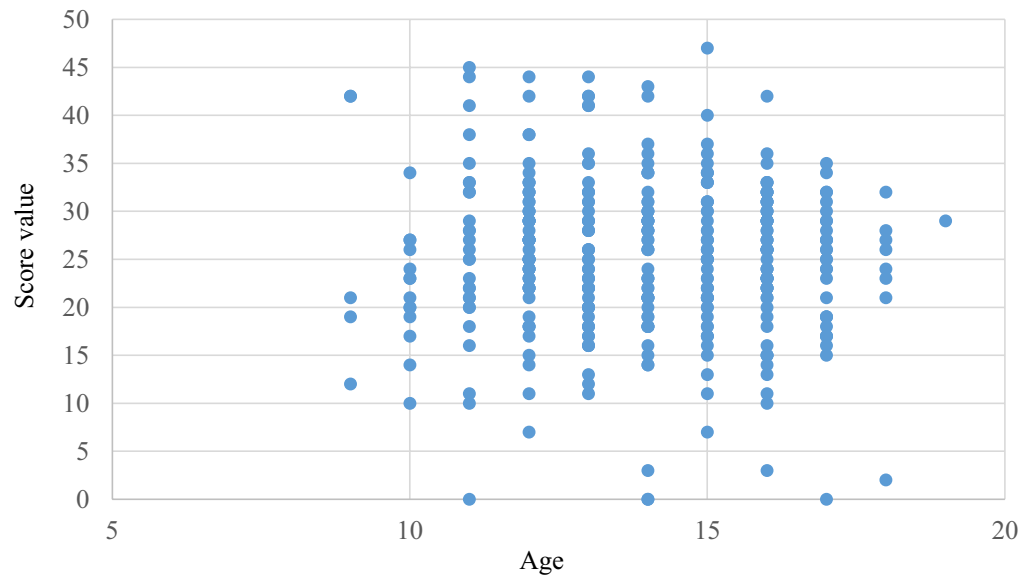

(D)

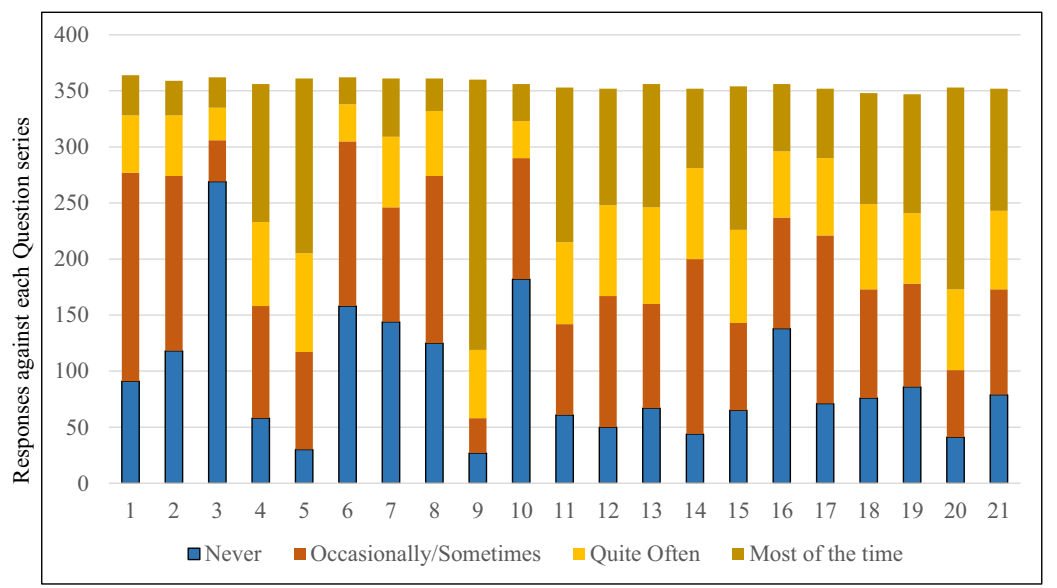

Question series 
hence the results may not be accurate to represent the wide population of the country as such. Assessment of Psychological morbidity with the quality of life and academic performance of children and adolescents need to be considered for future study. It is important to include the efficacy and adverse effects, as well as acceptability and issues for psychotherapy as well. Multicentre studies would help for future roadmaps to combat the hidden pandemic stress in children and adolescents revealed in our study.

Intervention strategies to be better prepared for future developments:

- Identification of the mental health as per the needs of the community, children, family levels.

- Strengthening the accessible mental health resources in communities for children and families.

- Implementation of evidence-supported practices that are scalable, expands access to care, and eliminates disparities.

- Collaborative care models that can address children's health care needs in low-resource settings.

- Enhance the telehealth capacity, services via text, telephone, or video access to a spectrum of services for individuals and expert consultation for people in lowresource communities.

- Screen time reduction may potentially reduce harmful effects.

- Estimation of the cost-benefit of the measures currently being adopted such as home schooling etc.

\section{Conclusions}

Children and adolescents are prone to accumulate several risk factors for mental health during COVID-19 pandemic. These factors and their relevance for stress-regulating coping processes may be disentangled through longitudinal real-time based studies. Though a mild level of stress was evident in children and adolescents as per survey of the Schools, but if unattended, the stress levels may increase. At this time point, it is important to focus on scale-up of mental health interventions and targeted learning strategies to reduce the inequality gap, and may require investment and training to be sustainable. It is utmost to give primary importance to assess the implications of policies enacted to contain the hidden pandemic on mental health of children and adolescents.

Supplementary Information The online version contains supplementary material available at https://doi.org/10.1007/s12144-022-02827-3.
Acknowledgements Authors are thankful to the Director, CSIR-NIS$\mathrm{cPR}$, New Delhi for providing all kind support and facility needed in completing the research study undertaken.

Funding information The research study did not receive any specific grant from funding agencies.

Data Availability Data sharing will be done on demand if any by contacting the individual authors.

\section{Declaration}

Ethics Approval and Consent to Participate The online questionnaire was administered to students with permission of respective school authorities. The informed consent of parents as well as informed assent of children were obtained online. There is no Institutional Ethical Committee for the survey studies as it does not deal with the treatment/sample collection/experimental procedure etc. therefore, Ethical approval is not applicable.

Consent for Publication Not applicable.

Conflict of Interest None.

\section{References}

Osika, W., Friberg, P., \& Wahrborg, P. (2007). A New Short Self-Rating Questionnaire to Assess Stress in Children International Journal of Behavioral Medicine., 14(2), 108-117.

Dandona, L. (2020). The burden of mental disorders across the states of India: the Global Burden of Disease Study 1990-2017. The Lancet Psychiatry., 7, 148-161.

Editorial. (2021). Nature Medicine, 27, 1655.

Zhang, Y., \& Ma, Z. F. (2020). Impact of the COVID-19 Pandemic on Mental Health and Quality of Life among local residents in Liaoning Province, China: a cross-sectional study. Int J Environ Res Public Health., 17(7), 2381.

Editorial. (2020). Mental health and COVID-19: change the conversation. The Lancet. Psychiatry., 7:463.

Aguiar Melo, M. C., \& de Sousa, S. D. (2020). Impact of social distancing on mental health during the COVID-19 pandemic: An urgent discussion. International Journal of Social Psychiatry., 66(6), 002076402092704.

Racine, N., McArthur, B. A., Cooke, J. E., Eirich, R., Zhu, J., \& Madigan, S. (2021). Global prevalence of depressive and anxiety symptoms in children and adolescents during COVID-19: a metaanalysis. JAMA Pediatr. Published online August, 9. https://doi. org/10.1001/jamapediatrics.2021.2482

Benton, T.D., Boyd, R.C., Njoroge, W.F.M. (2021) Addressing the global crisis of child and adolescent mental health.

Tiirikainen, K., Haravuori, H., Ranta, K., Kaltiala-Heino, R., \& Marttunen, M. (2019). Psychometric properties of the 7-item Generalized Anxiety Disorder Scale (GAD-7) in a large representative sample of Finnish adolescents. Psychiatry Res., 272, 30-35.

Polanczyk, G. V., Salum, G. A., Sugaya, L. S., Caye, A., \& Rohde, L. A. (2015). Annual research review: ameta-analysis of the worldwide prevalence of mental disorders in children and adolescents. J Child Psychol Psychiatry., 56(3), 345-365.

Marques de Miranda, D., da Silva, A. B., Sena Oliveira, A. C., \& Simoes-E-Silva, A. C. (2020). How is COVID-19 pandemic 
impacting mental health of children and adolescents? Int J Disaster Risk Reduct., 51, 101845.

Liang, L., Ren, H., Cao, R., Hu, Y., Qin, Z., Li, C., \& Mei, S. (2020). The effect of COVID-19 on youth mental health. Psychiatr. $Q$. https://doi.org/10.1007/s11126-020-09744-3

Fegert, J. M., Vitiello, B., Plener, P. L., \& Clemens, V. (2020). Challenges and burden of the Coronavirus 2019 (COVID-19) pandemic for child and adolescent mental health: a narrative review to highlight clinical and research needs in the acute phase and the long return to normality. Child Adolesc Psychiatry Ment Health, $14: 20$.
Sarkar, S., Gupta, R., \& Menon, V. (2017). A Systematic Review of Depression, Anxiety, and Stress among Medical Students in India. Journal of Mental Health and Human Behaviour., 22, (2) 88-96.

Publisher's note Springer Nature remains neutral with regard to jurisdictional claims in published maps and institutional affiliations. 